\title{
A CASA DA MORTE EM PETRÓPOLIS: O PATRIMÔNIO DE UMA MEMÓRIA TRAUMÁTICA
}

\section{THE HOUSE OF DEATH IN PETROPOLIS: THE HERITAGE OF A TRAUMATIC MEMORY}

\author{
Jonatan da Silva Ribeiro ${ }^{1}$
}

RESUMO: A “Casa da Morte”, localizada na Rua Arthur Barbosa, número i2o, Caxambu, na cidade de Petrópolis, funcionava como um ativo centro clandestino de repressão coordenado pelo CIE (Centro de Informações do Exército) no início dos anos de 1970. O imóvel foi cedido pelo empresário alemão Mário Lodders, era um espaço afastado das demais localidades e sem moradores ao redor, tornando-se um ambiente propício às sessões de tortura. Considerada como um dos piores porões de tortura da Ditadura Militar ficou também conhecida como a Casa dos Horrores e Codão, pois era quase impossível sair vivo do local, com exceção de Inês Etienne Romeu, a militante sobrevivente que relatou as violações que ali passou. Criada como um centro clandestino de opressão política, a Casa da Morte foi um dos piores centros de repressão da ditadura, em que o ódio e a violência contra os que não concordavam com as medidas e políticas da ditadura, conheceram o lado mais nefasto e sombrio do período.

Palavras-chave: Casa da Morte. Memória. Petrópolis.

ABSTRACT: The "Casa da Morte", located at Rua Arthur Barbosa, number 120, Caxambu, in the city of Petrópolis, operated as an active clandestine repression center coordinated by the CIE (Army Information Center) in the early 1970s. The property was provided by the German businessman Mário Lodders, it was a space far from other locations and with no residents around, making it an environment conducive to torture sessions. Considered as one of the worst torture cellars of the Military Dictatorship, it was also known as the Casa dos Horrores and Codão, as it was almost impossible to leave the place alive, with the exception of Inês Etienne Romeu, the surviving militant who reported the violations that happened there. Created as a clandestine center of political oppression, the Casa da Morte was one of the worst centers of repression of the dictatorship, in which hatred and violence against those who did not agree with the measures and policies of the dictatorship, knew the darkest and most nefarious side. of the period.

Keywords: House of Death. Memory. Petrópolis.

\section{INTRODUÇÃO}

A Casa da Morte, localizada no município de Petrópolis, mais especificamente no bairro Caxambu, foi utilizada durante a década de 1970 como um importante centro clandestino da

\footnotetext{
${ }^{1}$ Mestrando em Memória Social pelo Programa de Pós-Graduação da Universidade Federal do Estado do Rio de Janeiro. E-mail:jonatan3ı@gmail.com.
} 
Ditadura Militar, em que opositores ao regime eram presos, torturados e mortos. Innês Etienne Romeu foi a única que conseguiu ficar viva para contar a história. Com a promulgação da Lei de Anistia, Innês é solta e em depoimento a Ordem dos Advogados do Brasil conta todas as atrocidades que viveu na chamada Casa da Morte. Ao final da década de 1970 Innês volta a Petrópolis e reconhece a Casa em que ficara presa, por motivos políticos e ideológicos. Ao reconhecer a Casa Innês ganha repercussão nacional, inclusive chegando ao imóvel se encontra com o proprietário, na época o alemão Mário Lodders.

Tal revelação causou enorme repercussão na sociedade brasileira e principalmente petropolitana. $\mathrm{O}$ assunto volta a tona em 2010 com força total, quando vários movimentos sociais de Petrópolis se unem para lutar pela desapropriação e tombamento da Casa da Morte, reivindicando a instauração da Comissão Nacional da Verdade na cidade, para apurar os crimes cometidos durante a Ditadura Militar em Petrópolis.

Esses movimentos conseguem a institucionalização da Comissão Municipal da Verdade em Petrópolis e iniciam muitos atos e manifestações em torno do tema desapropriação e tombamento da Casa da Morte, bem como a criação de um Centro de Memória, Verdade e Justiça. Esse movimentos vão para as ruas e realizam passeatas, vigílias, peças teatrais, atos em frente a Casa da Morte e ganham grande visibilidade na mídia local e nacional.

Os movimentos sociais buscavam a desapropriação, tombamento e transformação da Casa da Morte em lugar de Memória, Verdade e Justiça, um patrimônio cultural.

Esse artigo insere-se dentro de uma pesquisa de lugares de memória e relação dos movimentos sociais, fazendo parte de uma pesquisa para fins de elaboração de uma dissertação de mestrado, buscando compreender a luta dos movimentos sociais em torno da Casa da Morte para seu tombamento, desapropriação e transformação em Centro de Memória, Verdade e Justiça. Para dar conta de tal objetivo, foi necessário seguir os caminhos da pesquisa bibliográfica, documental.

\section{CONTEXTUALIZAÇÃO TEÓRICA}

A palavra patrimônio tem um grande peso jurídico e possui como noção a ideia de “conjunto de bens direitos e obrigações de uma pessoa jurídica”. O patrimônio cultural seria um conjunto de bens culturais que devem ser preservados. Os monumentos eram construídos com o objetivo de homenagear e perpetuar a memória dos antepassados para as gerações futuras, um sinônimo de memória. (CHUVA; TEIXEIRA; LEAL,2013). 
Preservar a memória de fatos, pessoas ou ideais, por meio de constructos que as comemoram, narram ou representam, é uma prática que diz respeito a todas as sociedades humanas. E, pode-se dizer, um universo cultural e é essa função memorial que está por trás da noção de monumento em seu sentido original. Conceito, aliás, que se encontra vinculado ainda a uma produção simbólica, à instituição de um objeto como monumento por um grupo e à capacidade deste de atuar sobre a memória coletiva. (SANT'ANNA, 2003, p.46)

Os monumentos históricos tiveram sua origem na Revolução Francesa ${ }^{2}$ como atitude de reação ao vandalismo que ameaçava destruir os prédios históricos da França, possuem a forte função de testemunha da história ou até mesmo celebrações com as quais nos identificamos, muitos monumentos com o objetivo de rememoração homenagem ou celebração acabam se transformando em monumentos históricos. Os monumentos históricos marcam uma relação de distanciamento com a tradição e a memória, é conceituado como filho da modernidade. Não foi apenas o passado que precisou ser conservado, através de documentos escritos, o próprio presente precisava fundar sua legitimidade nesses documentos. (BELLOTO, 2006).

Na Europa, no século XVIII, surge uma segunda origem da noção de patrimônio, a partir da prática das coleções, sendo relacionado com coisas que por algum motivo perderam seu valor de uso, mas mantêm algum significado $O$ conceito de patrimônio tem derivação da ideia de monumento histórico e das coleções. (CHUVA; TEIXEIRA; LEAL,2013).

Para que qualquer objeto ou monumento seja transformado em patrimônio ele necessita passar por um processo de seleção que pressupõe decisões políticas, estratégicas sociais e práticas culturais. E se torna propriedade de uma nação. O tombamento é o ato oficial de reconhecimento do valor cultural de um bem. Lembrando o conceito de Halbwachs de que a memória coletiva, seria uma representação dos grupos sociais com a finalidade de mantê-los coesos e unidos. (CHUVA; TEIXEIRA; LEAL,2013).

O Decreto-Lei 25/1937, que organizou o Serviço do Patrimônio Histórico e Artístico Nacional, dispõe que a União manterá, para a conservação e exposição de obras históricas e artísticas de sua propriedade, tantos quantos museus forem necessários, devendo providenciar no sentido de favorecer as instituições de museus estaduais e municipais. (Capítulo V - disposições gerais; artigo 24).

\footnotetext{
${ }^{2} \mathrm{~A}$ Revolução Francesa representa um período fundador essencial, não apenas da história nacional daquele país, mas da humanidade, os acontecimentos de tal revolução criaram o conceito de Antigo Regime para exprimir o corte entre um antes sem volta e um depois. É aberta a concepção de um caminho para a modernidade. Ocorreu entre 1789 -1799.) (VOLVELLE,2019).
} 
O patrimônio material é todo monumento histórico consagrado, edifícios centros históricos, sítios urbanos e arqueológicos, são considerados bens imóveis. O surgimento da noção de patrimônio é indissociável da formação dos Estados-Nação, o patrimônio que queria-se preservar era um patrimônio pensado em termos nacionais, para representar o passado de uma nação. As primeiras legislações de preservação surgem na Europa no século XIX. Monumentos históricos com características relevantes eram aqueles que rememoravam aspectos e monumentos marcantes da história das nações.(CHUVA; TEIXEIRA; LEAL,2013). Pierre Nora, o historiador dos lugares de memória aponta de forma esclarecedora esse fenômeno que sociedade passa a atravessar:

À medida em que desaparece a memória tradicional, nós nos sentimos obrigados a acumular religiosamente vestígios, testemunhos, documentos, imagens, discursos, sinais visíveis do que foi, como se esse dossiê cada vez mais prolífero devesse se tornar prova em não se sabe que tribunal da história. O sagrado investiu-se no vestígio que é sua negação (NORA, 1993, p.15).

É interessante abordar que os conceitos de nação e nacionalidade ganham novos sentidos e significados a partir dos profundos movimentos de transformação do mundo ocidental, no final do século XVIII e no início do século XIX. Com a Revolução Francesa, ascensão da burguesia e das ideias liberais a Europa, que até então convivia com os reinos dinásticos, ou seja, governado por famílias, teve que se relacionar com formas mais amplas e menos discriminatórias de classificar os indivíduos. O conceito de cidadão passa a se sobrepor e o homem é entendido como portador de direitos e deveres.(CHUVA; TEIXEIRA; LEAL,2013).

Com as inúmeras depredações durante a Revolução Francesa, com revolucionários que destruíam símbolos da monarquia e do sistema estamental, com tamanha agressividade a esses imóveis, elaboram-se as primeiras defesas teóricas e práticas desses monumentos históricos, a criação de museus acaba sendo entendida como espaços destinados a guardar os tesouros ameaçados da nação. Surgia dessa maneira aos poucos na França a consciência de que havia um legado da cultura francesa que precisava ser preservada e valorizada, a idéia de conservar um testemunho do Antigo Regime ganha força em 1795, entre as primeiras ações de preservação foi a criação dos museus. De acordo com Le Goff (1990):

O papel essencial do museu é, em relação ao patrimônio cultural, de acordo com o Icom (1956), o de proteger os bens móveis incluídos em seu acervo. O decreto do Ibram reafirma o papel dos museus na guarda e proteção dos seus acervos de bens móveis. Os documentos, 
reunidos em arquivos são a materialização da memória de povos, sociedades e Estados. Nesse sentido, o documento não é apenas uma fonte de informação, mas também um suporte de memória, ou seja, é a base material na qual se registra a memória. (LE GOFF, 1990).

Em 1830 percebe-se a importância de rememorar o passado por meio de relíquias materiais, peças arqueológicas e os monumentos históricos, era necessário proteger obras e monumentos porque eram patrimônio da civilização. Desde o século XVIII mantinha-se a ideia de uma progressão rumo a uma sociedade cada vez mais civilizada. A civilização seria a expressão maior do progresso do "espírito humano". Uma luta por preservar o patrimônio é iniciada nesse período, expressando a ideia de homem civilizado e a consciência de uma ruptura com o passado e com a noção de progresso, nascia o homem civilizado, culto, urbano, tolerante, cortês e hospitaleiro. (CHUVA; TEIXEIRA; LEAL,2013).

Com a memória se entrelaça o processo de construção das identidades dos grupos sociais e, por conseguinte, dos sujeitos. Respeitar o direito dos indivíduos de se lembrar do seu passado é uma maneira de assegurar a preservação e o fortalecimento de suas identidades culturais, constituindo sua subjetividade (SANTOS, 2007).

No início do século XIX surge o nacionalismo como grande força ideológica e assume a ideia de nação como elemento fundamental para o progresso da humanidade. A História enquanto disciplina surge nesse século enquanto ciência, muito aproximada da preservação dos patrimônios, em I830 a França inaugura a proteção do patrimônio e todos os países passam a executar atividades de preservação. (CHUVA; TEIXEIRA; LEAL,2013).

No Brasil a necessidade de implantar medidas e instituições do poder público, objetivando preservar o patrimônio cultural surgiu ainda nos anos 1920. A institucionalização do Ministério da Educação e Saúde, criado em 1930, criou o Setor do Patrimônio Histórico e Artístico Nacional (SPHAN), a partir da criação de tal órgão o governo brasileiro assume a tarefa de preservação do patrimônio cultural brasileiro, até 1970 ficou a cargo desse órgão a proteção dos monumentos históricos da nação.

No Estado Novo, a institucionalização do patrimônio cultural está atrelada diretamente as mudanças na ideia de modernidade que atravessava a sociedade brasileira da década de 1920. A fundação de medidas para a proteção de patrimônio histórico e artístico levou em consideração a associação entre modernidade e tradição. Tais ideias circulavam entre os intelectuais que buscavam compreender novas formas de ver e entender o Brasil, em uma ampla empreitada política e intelectual. "Ser moderno era ser autêntico, era valorizar as próprias raízes sem imitações.” Duas grandes ideias de modernidade se opõe na década de 1920. A primeira que para 
ser moderno deveria a cultura brasileira igualar-se a alta cultura europeia, outra valorizava justamente a cultura popular e as tradições arquitetônicas do período colonial brasileiro.(CHUVA; TEIXEIRA; LEAL,2013).

Pontes, edifícios, casas de fazendas, oficinas, ferramentas, maquinários, louças, móveis estes e outros bens materiais preservados são vestígios do passado, são documentos, fontes históricas sujeitas a interpretações. O patrimônio pode ser entendido como referência de identidade para um grupo e a conservação desses vestígios tem assumido uma posição de obrigatoriedade. (CHUVA, 2013).

Conforme Milton Santos (1994) o lugar seria o locus do intersubjetivo, do coletivo. É a extensão do acontecer solidário, em que se entende por solidariedade a obrigação de se viver junto. Desta forma na construção da memória de um lugar deve se levar em conta um processo de memória compartilhada, a memória solidária, portanto uma memória que diga respeito a um grupo ou coletividade, nesta direção, uma memória coletiva. (HOFFMAN. p-36.2015).

O acesso aos arquivos auxilia no processo de construção da história, na medida em que permite que os cidadãos tenham conhecimento integral das informações neles contidos, que podem servir para esclarecer, ampliar e aprofundar as lembranças dos indivíduos. Michel de Certeau (2002, p.77) lembra que os lugares permitem e interditam as produções da história, tornando possíveis certas pesquisas em função de conjunturas e problemáticas comuns e, por outro lado, impossibilitando outras. Somente ampliando esse acesso, fica possível a construção de um conhecimento histórico-crítico possível e qualificado capaz de proporcionar maior respeito pelas memórias coletivas de uma sociedade. (NORA, 1993).

Se habitássemos ainda nossa memória, não teríamos necessidade de lhe consagrar lugares. Não haveria lugares porque não haveria memória transportada pela história. [...] Desde que haja rastro, distância, mediação, não estamos mais dentro da verdadeira memória, mas dentro da história. (NORA.r993, p. 8-9).

O patrimônio além de tantas funções que dele são exercidas, têm-se o papel social, político, econômico e também de um documento histórico a ser preservado, visando a produção de conhecimento sobre as sociedades humanas. No sentido mais público do patrimônio, os lugares têm a força de se impor como espaços de apoio ou comemoração de acontecimentos que o indivíduo pode ou não ter vivido. Esses lugares acabam funcionando como um suporte de acontecimentos experimentados pelo grupo ou coletividade a qual se possa pertencer. Lugares distantes ou fora do espaço-tempo do sujeito, também possibilitam a construção de lugares importantes para a memória de um grupo. É interessante compreender que uma noção 
fundamental de referência da memória de um grupo acaba estando pautada na durabilidade da materialidade desses espaços. (HOFFMAN. p-64.2015). O pesquisador Ulpiano Meneses faz uma importante reflexão em relação ao tema do patrimônio material:

Por se tratar de processos cognitivos encarnados (embodied cognitive processes), estão eles [os artefatos] marcados por uma inserção física no universo material. A exterioridade, a concretude, a opacidade, em suma, a natureza física dos objetos materiais, trazem marcas específicas à memória [...] Basta lembrar que a simples durabilidade do artefato, que em princípio costuma ultrapassar a vida de seus produtores e usuários originais, já o torna apto a expressar o passado de forma profunda e sensorialmente convincente (MENESES, I998, p.90).

Regina Abreu avança em sua concepção em relação a categoria de patrimônio e aponta que os lugares de memória ultrapassam a questão da materialidade e monumentalidade, abarcando registros, artefatos diversos, eventos e comemorações. Abreu dialoga com a concepção de patrimônios materiais e imateriais. Pode-se dizer que grande parte de registros, documentos são preservados em instituições de memória e formam instrumentos, pelos quais é possível contextualizar os testemunhos do passado que restaram na paisagem, assim as memórias coletivas se eternizariam muito mais em registros e documentos do que nas formas materiais da paisagem. (ABREU,1998.p.85).

Os museus, os memoriais ou centros de memória, são espaços físicos delimitados e mantêm características como tal, carregando um potencial de materialização da memória. Permitem a rememoração e a preservação das mais diversas narrativas e até mesmo são capazes de consolidar significados e produzir novas significações no campo da memória. (HOFFMAN. p-64.2015). Assim, "a verdade consiste em evitar o esquecimento, principalmente em relação ao que dói e incomoda.” Jacques Le Goff

A análise temática da memória permite reconhecer a existência do esquecimento, dos silêncios e dos não-ditos. O esquecimento pode resultar de uma opção individual ou coletiva de restringir certas lembranças ao essencial. A memória é seletiva, o esquecimento deve ser uma opção, principalmente no que diz respeito a experiências traumáticas. $O$ ato de lembrar é fundamental como mecanismo que permite a socialização da memória entre os membros do coletivo específico. (PADRÓS, 2010).

A memória é uma operação coletiva dos acontecimentos e das interpretações do passado que se quer salvaguardar. A referência ao passado serve para manter a coesão dos grupos e das instituições que compõe uma sociedade. Os lugares de memória nascem e vivem do sentimento 
que não há memória espontânea, que existe a necessidade de criar arquivos, a memória pendura-se em lugares. (POLLAK, 1989; NORA, 1993).

\begin{abstract}
Os lugares de memória são, antes de tudo, restos. A forma extrema onde subsiste uma consciência comemorativa numa história que a chama, porque ela a ignora. É a desritualização de nosso mundo que faz aparecer a noção. O que secreta, veste, estabelece, constrói, decreta, mantém pelo artifício e pela vontade uma coletividade fundamentalmente envolvida em sua transformação e sua renovação [...] os lugares de memória nascem e vivem do sentimento que não há memória espontânea, que é preciso criar arquivos, que é preciso manter aniversários, organizar celebrações, pronunciar elogios fúnebres, notariar atas, porque essas operações não são naturais (NORA, 1993, I213).
\end{abstract}

A memória opera a partir de um processo seletivo e pode se tornar uma arma política para as vítimas de guerras e genocídios, em que o esquecimento estabeleceu sua hegemonia. A memória individual revela apenas a complexidade das interações sociais vivenciadas por cada um. Halbwachs mostra que a memória individual não pode ser distanciada das memórias coletivas, a memória é constituída por indivíduos em interação, por grupos sociais, sendo as lembranças individuais, resultado desse processo. (ARAÚJO; SANTOS, 2007).

A UNESCO, é criada no contexto pós-guerra, em 1946, com objetivo de tomar atitudes em relação a preservação do patrimônio cultural dos Estado-parte ${ }^{3}$. Nesse sentido ocorrem mudanças nos discursos patrimoniais, assim como uma universalização de políticas públicas para a proteção do patrimônio cultural. Em 1948 a ONU admite a Declaração Universal dos Direitos Humanos, que além de exercer muitos outros papéis, reforça a função dos direitos culturais na promoção da paz universal. Nas três últimas décadas do século XX, a ideia de patrimônio da humanidade, foi gestada e regulamentada, observa-se sociedades ocidentais saturadas entre a amnésia e a vontade de não esquecer. (HARTOG. p.r17.2006).

\begin{abstract}
Sendo o esquecimento o elemento complementar da memória, também ele se manifesta através da ação dos agentes públicos e coletivos, seja pela ação do Estado, da família, sociedades, dos governos e grupos políticos etc. As memórias traumáticas relacionadas aos contextos de guerra vividos no século $\mathrm{XX}$, nas quais o Holocausto tornou-se o caso paradigmático, passaram a ser tema dos processos patrimoniais e de políticas de memória de diferentes países. Oscilando entre o que cada Estado acredita que deve ser lembrado ou esquecido, levando em consideração o impacto dos traumas coletivos, ou das reivindicações por justiça, o tema dos patrimônios em lugares de sofrimento tem avançado no contexto mundial. A UNESCO tem trabalhado, por exemplo, na "Rota dos escravos",
\end{abstract}

${ }^{3}$ Pode-se conceituar os Estado-parte como cada um dos países signatários do presente, em acordo ou aqueles que o aderem posteriormente. 
reconhecendo lugares relacionados ao tráfico de seres humanos da África, entre os séculos XVI e XIX, criando itinerários de conscientização e buscando o diálogo intercultural. ${ }^{4}$

Segundo Jelin (2017), as políticas de memorialização complementam o conjunto de demandas por Justiça e Verdade, que resultam das pesquisas da Comissão Nacional da Verdade, ou de lutas de grupos atingidos pela repressão. A tarefa de memorialização não é fácil e se torna bem complexa em sua concepção, culmina em um impulso ativo e um desejo de incidência política. Acaba se consolidando com um caráter de advertência e denúncia, através de espaços públicos, monumentos, placas, memoriais, museus, arquivos, concebe-se a materialização dessa memória “difícil”.(SCHINDEL, 2009, p. 67).

Os esquecimentos têm sido pauta de debate no meio acadêmico nos últimos anos. Silêncios públicos impostos muitas vezes pelo próprio Estado, esses silêncios têm levado os países latinoamericanos a tarefa de um "reenquadramento da memória", nessa demanda a prática de patrimonialização tem funcionado como uma espécie de reconhecimento simbólico e tem propiciado a construção de políticas públicas e o aprofundamento de tal questão.

A marcação pública de locais nos quais ocorreram violações dos direitos humanos é sempre um processo conflitivo, uma vez que depende da delegação de sentidos de grupos específicos, envolve subjetividades, ambiguidades e promove alterações e disputas, dependendo das conjunturas políticas do presente. Estes sítios de memória do horror (prisões, centros de tortura, locais de extermínio etc.) nos quais se encontram ainda vestígios de violações aos direitos humanos, carregados pela simbologia do horror, são distintos de outros sítios patrimoniais. Esses lugares possuem uma importância para o presente - no qual são designados como patrimônio - uma vez que, a partir do contexto dos usos nesse presente, servem a uma projeção de futuro, entendendo que esses sítios de memória têm um significado afetivo para os que sofreram direta ou indiretamente com a violência de Estado, congregando também um capital político e um potencial pedagógico, possuindo, ainda, um valor jurídico-documental para as vítimas que buscam reparações públicas pelos crimes perpetrados. (FUNARI, MARCHI, POLONI. 2019).

Os museus, memoriais e monumentos acabam exercendo a função de "abrigar” memórias, muitas vezes traumáticas, no sentido de que futuras gerações conheçam e não permitam que atrocidades e violações aconteçam novamente. Trazendo uma mensagem importante, esses espaços representam uma narrativa do trauma e são capazes de reafirmar a noção do "nunca mais". É interessante que instituições, permitem, por meio de suas memórias, uma reparação moral para

${ }_{4}^{4}$ Disponível em:http://www.unesco.org/new/en/social-and-humansciences/themes/slave-route/. Acesso em: 6 jan. 2019. Um dos sítios de memória associados a essa rota em contexto brasileiro é o Cais do Valongo, no Rio de Janeiro, considerado o traço material mais significativo do tráfico de escravos no continente americano e, certamente, um importante potencial objeto de estudos para as temáticas da Arqueologia da Repressão e da Resistência no País. 
as vítimas que sofreram violações do Estado e agressões aos direitos humanos sofridos por determinados grupos da sociedade. (HOFFMAN, p.57.2015).

Desde o final do século XX, percebe-se uma necessidade da instituição de museus em lugares de memória traumática, como catástrofes, guerras, genocídios, contextos de escravidão, tortura, opressão, sofrimentos e toda sorte de memórias de dor, muitas vezes a transformação desses espaços em lugar de memória acaba sendo impulsionada por grupos sociais. Nessa demanda observa-se a criação de muitos museus com essas características. Museus para a paz, Museus de memórias traumáticas, Museus de memórias difíceis, Museus de direitos humanos, são novas noções atribuídas a ideia de museu, geralmente envolvem memórias sensíveis e buscam uma reparação moral para as vítimas, além de almejar uma transformação da sociedade. Os espaços que trabalham com memórias de trauma acabam estabelecendo uma conexão com o passado e o presente (HOFFMAN, p.91, 2015).

Hoffman também aponta para a existência de "feridas coletivas", que geralmente tem caráter simbólico, e se estabelecem por meio de violências e muitas vezes constituem uma identidade coletiva. Ricouer sintetiza de forma clara e simples tal afirmativa:

[...] não existe nenhuma comunidade histórica que não tenha nascido de uma relação que se possa comparar sem hesitação à guerra. Aquilo que celebramos como acontecimentos fundadores são essencialmente atos violentos legitimados posteriormente por um estado de direito precário. A glória de uns foi humilhação para outros. À celebração, de um lado, corresponde a execração, do outro. Assim se armazenam, nos arquivos da memória coletiva, feridas simbólicas que pedem uma cura (RICOEUR, 2007, p.92).

Michael Pollak traz a noção de memórias subterrâneas que seriam, memórias "clandestinas" que são transmitidas de uma geração para outra, geralmente por meio da oralidade, que sobrevivem por anos e aguardam o momento certo para serem reveladas. As memórias subterrâneas não estão fadadas ao esquecimento, ficam silenciadas e se caracterizam como uma forma de resistência e vão contra o discurso de uma memória oficial e que domina. (POLLAK,1989).

\section{METODOLOGIA}

Cellard (2008,p.296, apud ALMEIDA; GUINDANI; SÁ-SILVA, 2009,p.7) mostra que ao privilegiar uma abordagem mais ampla de documento, a Escola de Annales, uma das linhas teóricas da História, estende para além do texto dos arquivos oficiais, a noção de documento. 
Desta forma, segundo o autor anteriormente citado, o conceito de documento passa a ser: "tudo o que é vestígio do passado, tudo o que serve de testemunho, é considerado como documento ou 'fonte”" (CELLARD, 2008, p. 296). E mais: "pode tratar-se de textos escritos, mas também de documentos de natureza iconográfica e cinematográfica, ou de qualquer outro tipo de testemunho registrado, objetos do cotidiano, elementos folclóricos, etc” (p. 297).

Oliveira (2007,p.69, apud ALMEIDA; GUINDANI; SÁ-SILVA, 2009,p.6) faz uma importante distinção entre pesquisa bibliográfica e pesquisa documental. Para essa autora a pesquisa bibliográfica é uma modalidade de estudo e análise de documentos de domínio científicos tais como livros, periódicos, enciclopédias, ensaios críticos, dicionários e artigos científicos. Como característica diferenciadora ela pontua que é um tipo de "estudo direto em fontes científicas, sem precisar recorrer diretamente aos fatos/fenômenos da realidade empírica” (p.69). Argumenta que a principal finalidade da pesquisa bibliográfica é proporcionar aos pesquisadores o contato direto com obras, artigos ou documentos que tratem do tema em estudo: "o mais importante para quem faz opção pela pesquisa bibliográfica é ter a certeza de que as fontes a serem pesquisadas já são reconhecidamente do domínio científico" (p. 69). Ela se posiciona sobre a pesquisa documental: “a documental caracteriza-se pela busca de informações em documentos que não receberam nenhum tratamento científico, como relatórios, reportagens de jornais, revistas, cartas, filmes, gravações, fotografias, entre outras matérias de divulgação" (p.69).

\section{RESULTADOS}

Os Centros Clandestinos de Detenção e Tortura (CCDT 's), funcionaram durante a Ditadura Militar. Por meio da política da Doutrina de Segurança Nacional, todo opositor ao Regime Militar passa a ser duramente oprimido, têm-se a ideia de um "inimigo interno" (ALVES,1985. PADRÓS, 2010). Como ferramenta na luta pela contenção da oposição o Estado instaura os centros clandestinos como um aparato repressor do governo, e uma forma de coletar informações e reprimir tais inimigos.

Uma cultura do medo é imposta a sociedade, qualquer indivíduo era suspeito de estar envolvido com a subversão. Padrós aponta para a aplicação de uma violência, que afetava diretamente a vítima. O Relatório da Comissão Nacional da Verdade, mostra que nesses locais clandestinos ocorriam atividades tando de identificação, quanto de combate acirrado aos opositores do governo, era também constante o recrutamento e monitoramento de pessoas para atuar como infiltrados nas organizações oposicionistas. (RCNVCC, 2014). 
A função de um CCDT dentro da lógica repressiva era marcada pelo desenvolvimento de atividades como serviços de inteligência e de combate efetivo aos opositores por meio de sequestros, pelo uso da tortura como forma de interrogatório para obtenção de informações e, em contrapartida, promover a "quebra" dos indivíduos como forma de desestruturação física e psíquica (BNM, I985; FICO, 200I).

Sobre a Casa da Morte, a Comissão Nacional da Verdade aponta os seguintes elementos:

Funcionou em Petrópolis, RJ entre os anos de 1971 e 1974 Estava ligada ao Centro de Operações de Defesa Interna/Destacamento de Operações de Informações - CODI-DOI - do I Exército (Rio de Janeiro) e ao Centro de Informações do Exército - CIE. Este CCDT atuava como um braço secreto dos DOI's com o objetivo de realizar sequestros, infiltrar agentes nas organizações de esquerda, realizar translado de presos, interrogatórios sob tortura, assassinatos, ocultação de cadáveres, entre outras atribuições. Houve uma única sobrevivente Inês Etienne Romeu, que permaneceu presa $\mathrm{e}$ torturada.(RCNVCC, 2014, p.17-21).

Com a Lei de Anistia no final dos anos 1970 e a libertação de Inês Etienne Romeu, foi possível a oportunidade de que ela contasse a triste história de sua prisão política em Petrópolis, prestando um depoimento a Ordem dos Advogados do Brasil (OAB). Inês reuniu uma comitiva de parlamentares e advogados, com a presença da imprensa, inclusive da própria região de Petrópolis, e um processo movido pela Justiça Federal de Petrópolis contra Mário Lodders, foram preponderantes, para que em 198I, pela primeira vez, fosse diagnosticado a presença da Ditadura Militar em Petrópolis, por meio de um centro clandestino de tortura, que ficara conhecido como a "Casa da Morte”. Lodders, proprietário do imóvel, cedeu na época a Fernando Sérgio Ayres da

Motta, para uso e operação do DOI-CODI, subordinado ao Centro de Informações do Exército (CIE). (Comissão Municipal da Verdade de Petrópolis. p.19.2018).

Possivelmente, de acordo com o Relatório Final da Comissão Nacional da Verdade, a Casa da Morte e sua prática de terror teriam funcionado entre os anos de 1971 a 1974, tal conclusão se baseia no cruzamento das datas dos desaparecimentos ou morte dos militantes que faziam oposição a Ditadura Militar, membros de grupos clandestinos que podem ter passado pela Casa, descritos por Innês Etienne Romeu, e o depoimento dos agentes da repressão. A principal função daquele espaço seria, tortura, mortes e a obtenção de informações retiradas das principais lideranças contrárias a forma de governo vigente na época. As informações eram usadas para desarticular os movimentos de esquerda que combatiam o regime militar. (CMVP. p.I29. 2018).

A Casa da Morte, em Petrópolis (RJ), foi um dos principais centros clandestinos utilizados pelo regime militar para a prática de graves violações de direitos humanos: detenção ilegal e arbitrária, tortura, execução e desaparecimento forçado. As informações mais importantes a seu respeito têm origem no depoimento de sua única sobrevivente, Inês Etienne Romeu, e são complementadas e corroboradas por documentos produzidos pelo próprio Estado, bem como por testemunhos de ex-presos políticos e depoimentos de agentes da repressão (BRASIL, 2014, p. 532). 
A Casa da Morte em Petrópolis serviu por muito tempo como um centro em que os horrores da tortura e repressão do governo vigente foram incisivos, o que levou a Casa a ser considerada um dos piores porões da Ditadura Militar. O depoimento de Innês Etienne Romeu, que conseguiu sobreviver, assim como o reconhecimento do imóvel feito por ela fora primordiais na descoberta da Casa da Morte em Petrópolis.

A partir de 2010 com a luta dos movimentos sociais para a desapropriação e tombamento do imóvel intensifica-se a construção de memórias em torno da Casa da Morte, muitos fenômenos podem ser levados em consideração, como à vontade de memória, o desejo de lembrar e preservar essa memória que resistiu durante a Ditadura Militar e essa criação de grupos na luta pela instituição de um Centro de Memória, Verdade e Justiça, atestam a grande necessidade de se lembrar discutida por Hyssen (2014) na contemporaneidade.

Quando esses grupos vão para a frente da Casa da Morte, buscando a legitimação de uma memória e a necessidade da transformação da Casa em museu, eles mostram que a memória é capaz de resistir a tortura, ao tempo e de atravessar gerações.

\section{CONCLUSÕES}

Não foi tarefa fácil depois de um período considerável localizar e identificar esses espaços de tortura, porém com o árduo trabalho da Comissão Nacional da Verdade, muitas tentativas de silenciamento, em relação a prática de tortura na Ditadura Militar, são rompidas. A CNV conseguiu sistematizar e apontar esses lugares. Interessante que a pesquisa acaba se pautando no passado desses imóveis e também em seu uso no presente e ressalta que tais construções passaram a ser muitas vezes de utilidade pública ou privada em que as pessoas que ali frequentavam, não tinham sequer noção dos horrores e do passado tenebroso por trás daquelas edificações. (BARETTA. p.129.2017).

Repleta de subjetividades a Casa da Morte e os atores envolvidos em sua narrativa se tornou palco de grandes desejos, expectativas, disputas, divisões, ideologias, políticas, sentimentos, deslocamentos, agrupamentos e divisões que levam a Casa da Morte a abrigar uma vasta complexidade em suas memórias. 


\section{REFERÊNCIAS BIBLIOGRÁFICAS}

ABREU, Regina. Museus no contemporâneo: entre o espetáculo e o fórum.In:Loures Oliveira, A.P.P. e Monteiro Oliveira, L. (org.) Sendas da Museologia.Ouro Preto, UFOP. 2012.

BARETTA, Jocyane Ricelly. A importância da Materialidade dos Centros Clandestinos de Detenção e Tortura para contar histórias da Ditadura no Brasil.Aedos, Porto Alegre, v. 9, n. 2I, p. I09-131, Dez. 2017

BARETTA, Jocyane Ricelly. Arqueologia e a construção de memórias materiais da Ditadura Militar em Porto Alegre/RS (1964/1985).2015. Dissertação (Mestrado) - Programa de PósGraduação em História. Instituto de Filosofia e Ciências Humanas, Universidade Estadual de Campinas, Campinas, 2015. Disponível em: https://bit.ly/2AMGdND. Acesso em: 29 ago. 2018. BELLOTO, Heloísa Liberalli. Arquivos Permanentes. Tratamento do documental. RJ: FGV,2006 BRASIL. Comissão Nacional da Verdade: volume I. 2014.COMISSÃO NACIONAL DA VERDADE. Apresentação sobre torturadores e carcereiros identificados por Inês Etienne Romeu ante a Comissão Nacional da Verdade. Acesso em 15/o3/2014. Disponível em:

http://www.cnv.gov.br/images/pdf/petropolis/torturadores_carcereiros. $\mathrm{Pdf}>$

COMISSÃO NACIONAL DA VERDADE. Relatório preliminar de pesquisa sobre a Casa da Morte de Petrópolis. 2014. Disponível em: $\langle$ http://www.cnv.gov.br/images/pdf/petropolis/Versao_final_-_Casa_da_Morte__relatorio_preliminar_revisado.pdf $>$

CORREÂ, Maria Letícia. História do Brasil IV.v2 /Maria Letícia Corrêa, Mônica Piccolo Almeida -Rio de Janeiro: Fundação Cecierj, 2013.

CHIAVENATO, Júlio José. O golpe de 64 e a ditadura militar. São Paulo: Editora Moderna, 1997 CHUVA, Marcia. "Intelectuais e Estado: disputas em torno da noção de patrimônio nacional" in: ANAIS DO MUSEU HISTÓRICO NACIONAL. Vol. 37 (2005), pp. 41-5I.

HALBWACHS, Maurice. A memória coletiva. São Paulo: Centauro, 2004 JELIN, E. 2002. Los trabajos de la memória. Madrid: Siglo XXI.LE GOFF, J. 1994. História e memória. 3. ed., Campinas, SP: Ed. Unicamp.

JELIN, Elizabeth.Los trabajos de la memoria. España: Siglo Veintiuno editores, 200 .

NORA, P. 1993. “Entre memória e história: a problemática dos lugares”. Projeto História, n. Io, p. 7-28.

ORDEM DOS ADVOGADOS DO BRASIL (OAB). Processo no F-CDH-oiz/8o. Rio de Janeiro:Conselho Federal - Comissão de Direitos Humanos, ı98o. 